\title{
Article \\ Numerical Simulation of Rockfill Materials Based on Fractal Theory
}

\author{
Hongxing Han ${ }^{1, * \mathbb{D}}$, Yun $\mathrm{Ma}^{1}$, Wei He ${ }^{1}$, Weifang Yang ${ }^{1}$ and Xudong $\mathrm{Fu}^{2}$ \\ 1 School of Civil Engineering and Architecture, Xinxiang University, Xinxiang 453003, China; \\ yunma@xxu.edu.cn (Y.M.); weihe@xxu.edu.cn (W.H.); yangweifang@xxu.edu.cn (W.Y.) \\ 2 School of Civil Engineering, Wuhan University, Wuhan 430072, China; xdfu@whu.edu.cn \\ * Correspondence: hxhan@whu.edu.cn
}

check for updates

Citation: Han, H.; Ma, Y.; He, W.; Yang, W.; Fu, X. Numerical Simulation of Rockfill Materials Based on Fractal Theory. Appl. Sci. 2022, 12, 289. https://doi.org/ 10.3390/app12010289

Academic Editors: Arcady Dyskin, Junwon Seo and Jong Wan $\mathrm{Hu}$

Received: 13 October 2021

Accepted: 24 December 2021

Published: 29 December 2021

Publisher's Note: MDPI stays neutral with regard to jurisdictional claims in published maps and institutional affiliations.

Copyright: (c) 2021 by the authors. Licensee MDPI, Basel, Switzerland. This article is an open access article distributed under the terms and conditions of the Creative Commons Attribution (CC BY) license (https:// creativecommons.org/licenses/by/ $4.0 /)$.

\begin{abstract}
With the use of the particle flow code in two dimensions, a fractal model is established with the number of particles of different particle fractions used as the statistics to study the fractal characteristics of particle size distribution. Numerically simulated specimens obtained by four scale methods are subjected to the relative density test and the biaxial compression test to explore the influences of fractal dimension $D$ on the macroscopic and mesomechanical properties of specimens, as well as to study the relationship between fractal dimension $D$ and different mechanical performance indexes. Results show that the particle size distribution of each of the four groups after scale exhibits fractal characteristics, with the fractal dimension $D$ ranging from 1.27 to 2.03. The number of fine particles in the specimen increases with the fractal dimension $D$, the particle aggregates become more compact, the macroscopic mechanical properties of the specimens are improved, and a linear relationship exists between the fractal dimension $D$ and different mechanical performance indexes. A large fractal dimension $D$ corresponds to a great mesoparticle coordination number.
\end{abstract}

Keywords: numerical simulation; rockfill materials; fractal model; mesomechanical properties

\section{Introduction}

Rockfill materials have been used as a main filling material for earth-rockfill dams, especially with the construction of high earth-rock dams in recent years. Thus, their functional characteristics need to be acquired accurately. In practical engineering, the particle size of rockfill materials is $400-600 \mathrm{~mm}$ and even reaches more than $1000 \mathrm{~mm}$. Given the limitations of laboratory test instruments, rockfill materials that exceed the permissible maximum particle size needs to be scaled. To determine the mechanical properties of rockfill materials on site, analog simulation is adopted in laboratory tests to fabricate test specimens that are consistent with the prototype rockfill materials in terms of the internal structure, thereby determining the engineering features of the prototype rockfill materials. Thus far, many scholars at home and abroad have conducted extensive research on factors that influence the size effect of rockfill materials from the aspects of scale method [1-4], specimen size [5-7], particle shapes [8-10], and scale ratio [11-13]. Their research methods are still dominated by conventional triaxial tests [2-4,6-8], and laboratory tests are limited by test conditions and costs, as well as difficulties in analyzing changes in the internal mesoscopic mechanisms of rockfill materials. Numerical simulation can be used to compensate for the shortcomings of laboratory tests, allowing for the real-time monitoring of the law of evolution of rockfill materials in the internal crack, energy and mesostructured [14,15].

Since its introduction [16], fractal theory has made some valuable achievements in the aspects of rock fracture [17], soil particle morphology [18,19], and rockfill materials breakage [20-22]. Fractal geometry theory was drawn into the gradation of rock-fill materials. It is found that the truncation error is one of the main factors affecting the density scale effect of rockfill materials [23]. 
Wu et al. [20] studied the correspondence between the relative density (RD) of rockfill materials and the fractal dimension based on fractal theory and explained the four common scale methods. Turcotte et al. [24] found that, with particles being crushed increasingly, the initially distributed particles show similar fractal distributions. Bouzeboudja and Melbouci [25] selected two methods for calculating the fractal dimension and explored the relations among the fractal dimension and the size, shape, and properties of particles. Hou et al. [26] found that the fractal dimension increases with the confining pressure in the test specimen, and the fractal dimension depends on the particle size distribution. Muto et al. [27] observed crushed particles of a rock fracture zone under an optical microscope and found that the fractal dimension that was obtained on site was apparently higher than those measured in laboratory tests but close to the theoretical fractal dimension. The above findings are mainly concentrated in the aspects of fractal dimension and particle breakage, scale methods, and mechanical properties, and the research techniques are mostly based on Tyler's fractal model for mass distribution [19]. At present, most scholars have studied the mechanical properties of rockfill materials using the quality fractal model proposed by Tyler, but the fractal model is not reported with the number of particles between different particle groups as the statistical number in the newspaper.

In this paper, with the use of the particle flow code in two dimensions and on the basis of fractal theory, a fractal model is established with the number of particles of different particle fractions as the statistics to explore the fractal characteristics of the particle size distribution. Using the fractal model, the original grading curve of rockfill materials is scaled in four conventional scales. Taking the fractal dimension of the scaled sample as the index reflecting its structural parameters, the relative density test and biaxial compression test under different fractal dimensions are carried out, and the physical and mechanical properties of rockfill materials under different fractal dimensions are studied. The research results provide a new method for studying the mechanical properties rockfill materials.

\section{Grading Scale Methods}

The commonly used scale methods for the grading of rockfill materials include screening, similar gradation, equivalent substitution, and mixing. Screening refers to the removal of particles that exceed the permissible maximum particle size. Thus, the content of fine particles smaller than $5 \mathrm{~mm}$ is relatively increased with the mechanical properties of granular materials. Screening is suitable only when few particles exceed the permissible maximum particle size. Self-similarity gradation remains the coefficient of curvature of gradation, and the nonuniformity coefficient remains unchanged with the increasingly larger content of fine particles and the smaller content of coarse particles, thus changing the mechanical properties. Equivalent substitution ensures that the content of coarse particles and that of fine particles are unchanged even with changes in the grading, nonuniformity, and curvature coefficients of the coarse particles. In mixing, the particle size is reduced by self-similarity gradation at a certain scale, and the equivalent substitution is used. Whatever scale method is chosen, the relationship of the coarse and fine particles in the filling process changes markedly, and the mechanical properties of the rockfill materials change significantly before and after scaling. Therefore, how a reasonable scale method should be chosen awaits further study.

To investigate the influences of the fractal dimension $D$ on the mechanical properties of rockfill materials, this paper chooses the grading curve designed in [28] and the grading curves obtained from the four scale methods; the maximum particle size after scale is $60 \mathrm{~mm}$. The scale methods are equivalent substitution, screening, self-similarity gradation, and mixing, which are denoted by DL, TC, XS, and $\mathrm{HH}$, respectively. The grading curve designed for rockfill materials and the gradation characteristic curve after scaling are shown in Figure 1. 


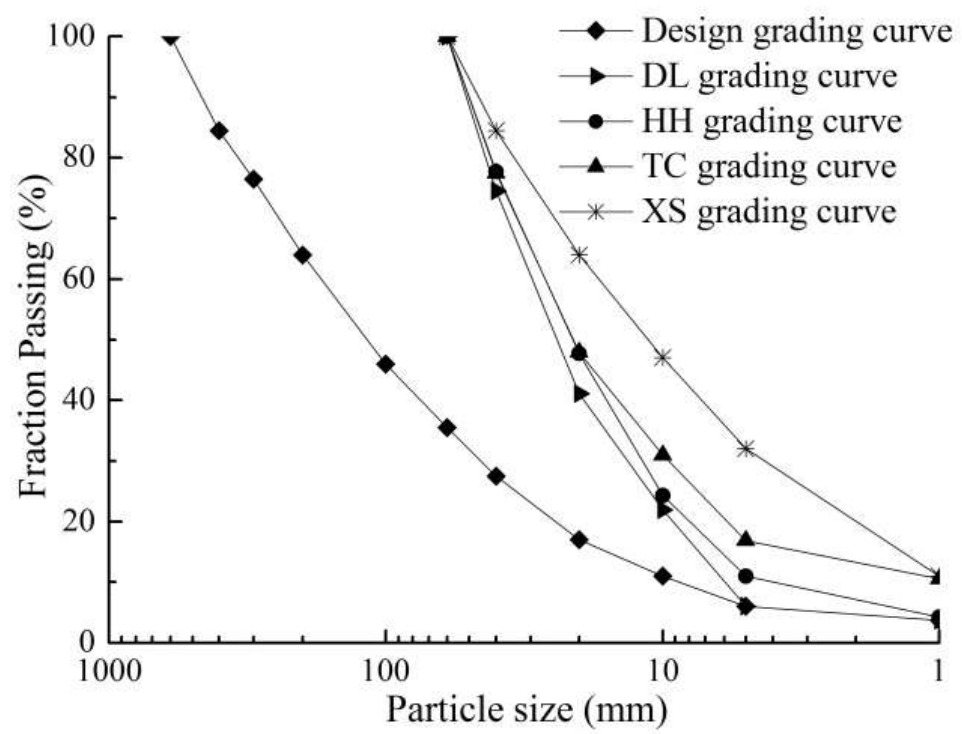

Figure 1. Grading curves.

\section{Fractal Model}

The particle shape and size distribution of rockfill materials, as well as the clearance between particles and surface behaviors, have certain influences on compactness. These features are random in a certain range and are difficult to describe in the conventional language of mathematics. Therefore, the fractal dimension $D$ is taken as a macro-meso mechanical index to study rockfill materials, with the following basic definition based on fractal theory:

$$
N \propto\left(\frac{1}{r}\right)^{D}
$$

where $r$ represents the graphic measure, $N$ represents the measured value from the corresponding $r$ graph, and $D$ represents the fractal dimension of the graph.

Given that the numerically simulated specimen makes obtaining the number of particles of different particle fractions easier, the particle aggregate inside the numerically simulated specimen is considered a measure, and the composition of particles is a structural pattern without characteristic length. In this paper, a fractal model that is different from that presented by Turcotte [21] is established, with the ratio of the upper limit $d_{i}$ for the particle size of the particle fraction to the maximum particle size $d_{\max }$ of the specimen as the measure, and the ratio of the number of particles of the particle fraction to the total number of particles of the specimen as the measured value. Then, the particle size distribution function reflected by the number of particles is

$$
\frac{N_{i}}{N_{\text {sum }}} \propto\left(\frac{d_{i}}{d_{\max }}\right)^{-D}
$$

where $N_{i}$ represents the number of particles with a particle size within the range of $\left[d_{i-1}, d_{i}\right]$, $N_{\text {sum }}$ represents the total number of particles of the specimen, $d_{i}$ represents the upper limit for the particle size of the particle fraction, and $d_{\max }$ represents the maximum particle size in the specimens.

With the introduction of a proportional constant $C$, Equation (2) can be expressed by

$$
\frac{N_{i}}{N_{\text {sum }}}=C\left(\frac{d_{i}}{d_{\max }}\right)^{-D}
$$

From Equation (3), the number $N_{i}$ of particles in the particle fraction is related to the proportional constant $C$, the upper limit $d_{i}$ for the particle size of the particle fraction, 
the maximum particle size $d_{\max }$ inside the specimen, and the fractal dimension $D$ of the specimen. This equation gives the basic mathematical model for the particle size distribution of the numerically simulated specimen. The numerically simulated specimen during particle formation has no particle breakage, so $N_{i} \propto\left(d_{i}\right)^{-D}$. With the introduction of another proportional constant $\lambda$, Equation (3) can be expressed by

$$
N_{i}=\lambda\left(d_{i}\right)^{-D}
$$

Both sides of Equation (4) are operated logarithmically. Then

$$
\lg \left(N_{i}\right)=-D \lg \left(d_{i}\right)+\lg \lambda
$$

Equation (5) presents the method of solving the fractal dimension. The double logarithmic chart of the number of particles in the particle fraction $N_{i}$ and the upper limit for the particle size of the particle fraction $d_{i}$ are plotted. The regression curve is fitted by using the least squares method, and the inverse of the slope of the line is also the fractal dimension $D$. The number of particles in the numerically simulated specimen is shown in Table 1. Linear fitting $\lg \left(d_{i}\right)$ and $\lg \left(N_{i}\right)$ is shown in Figure 2.

\begin{tabular}{|c|c|c|c|c|c|c|c|}
\hline \multirow{2}{*}{$\begin{array}{c}\text { Scale } \\
\text { Method }\end{array}$} & \multicolumn{5}{|c|}{ Particle Size (mm) } & \multirow{2}{*}{$\begin{array}{c}\text { Fractal } \\
\text { Dimension }\end{array}$} & \multirow{2}{*}{$\begin{array}{l}\text { Correlation } \\
\text { Coefficient }\end{array}$} \\
\hline & $60 \sim 40$ & $40 \sim 20$ & $20 \sim 10$ & $10 \sim 5$ & 5 & & \\
\hline $\mathrm{DL}$ & 20 & 72 & 164 & 544 & 461 & 1.27 & 0.839 \\
\hline $\mathrm{HH}$ & 18 & 65 & 201 & 458 & 850 & 1.49 & 0.935 \\
\hline $\mathrm{TC}$ & 18 & 64 & 146 & 487 & 1314 & 1.64 & 0.978 \\
\hline XS & 13 & 45 & 148 & 521 & 2500 & 2.03 & 0.992 \\
\hline
\end{tabular}

Table 1. The number of particles for numerical samples and test results.

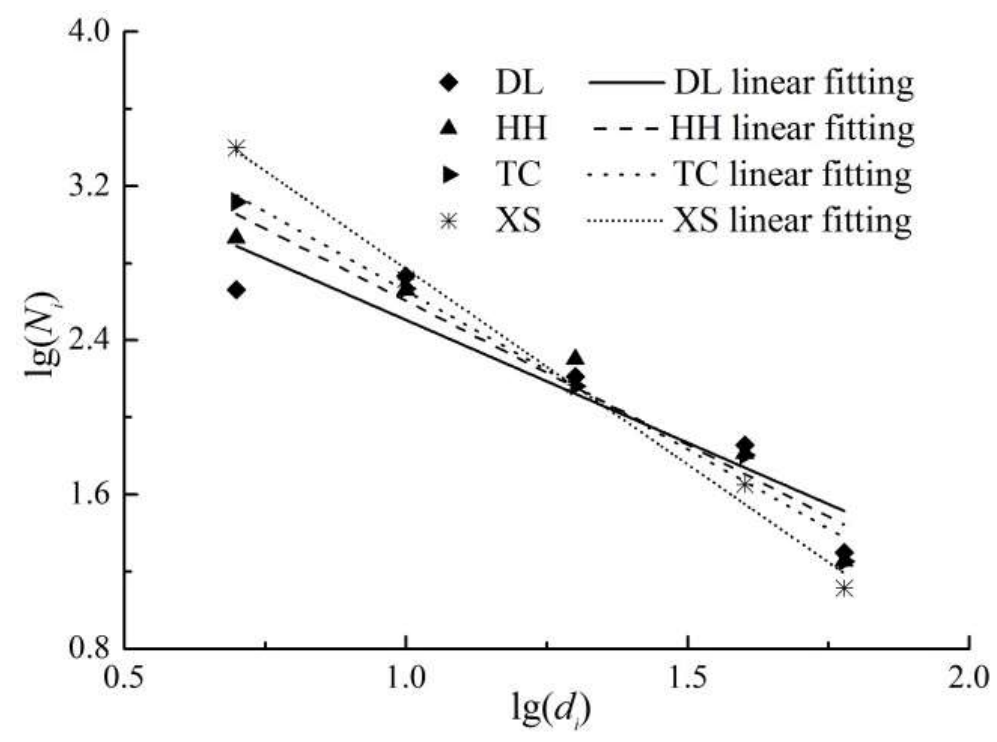

Figure 2. Linear fitting between $\lg \left(d_{i}\right)$ and $\lg \left(N_{i}\right)$.

The fitting results in Table 1 and Figure 2, except for the relatively poor linear correlation (correlation coefficient $\mathrm{R}^{2}=0.838$ ) that corresponds to the numerically simulated specimen from the equivalent substitution, indicate that the numerically simulated specimens from the other three scale methods show better linear fitness, with a correlation coefficient within the range of 0.935-0.992. These findings indicate that the fractal dimension $D$ can basically reflect the changing trend of particle size distribution. Only the equivalent substitution can cause a greater disturbance to the particle size distribution. 


\section{Analysis of the Results of the Numerical Test}

\subsection{Compactness Test}

$\mathrm{RD}$ is an important indicator for controlling the shear strength of granular material [3]. Thus, the numerical test on RD is performed to analyze the influences of the fractal dimension $D$ on the compactness of rockfill materials. The maximum void ratio $e_{m a x}$ and minimum void ratio $e_{\min }$ of the numerically simulated specimen must be determined first. In this paper, the maximum void ratio is determined by using a method presented by Deluzarche et al. [13], that is, frictional particle aggregate under the action of dead load reaches the loosest state defined by the natural accumulation state. However, the minimum void ratio is obtained by compressing the rigid boundary of frictionless particle aggregate in all directions. The specimen size is $\varphi 300 \mathrm{~mm} \times 600 \mathrm{~mm}$, and the maximum particle size $d_{\text {max }}$ is $60 \mathrm{~mm}$. The relationship between dense degree index and the fractal dimension $D$ is shown in Figure 3.

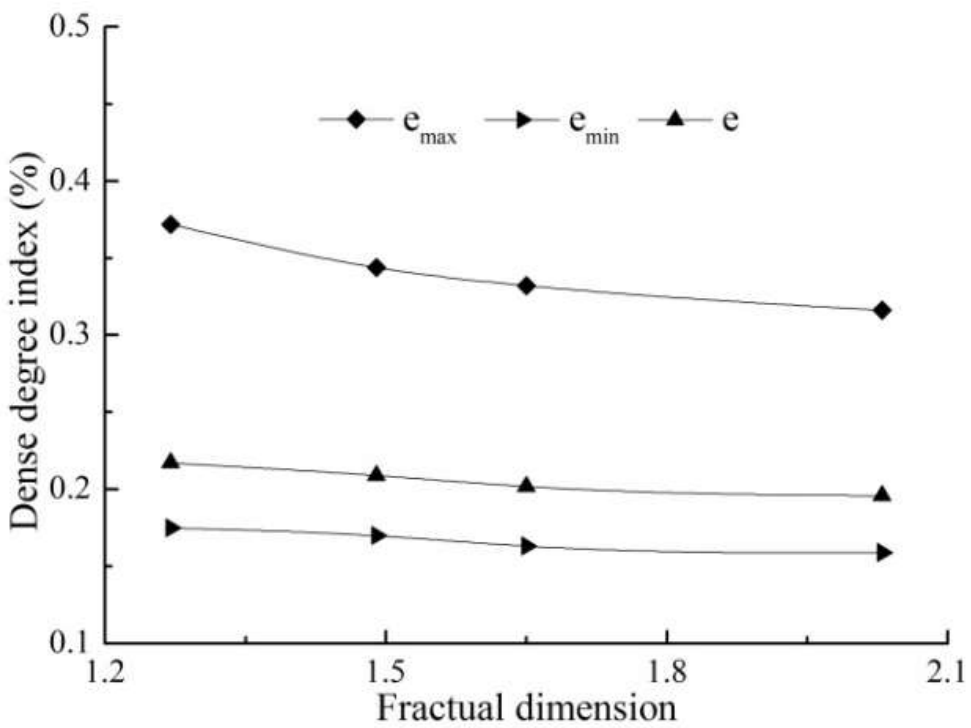

Figure 3. Relationship between dense degree index and fractal dimension.

Figure 3 shows that the fractal dimension $D$ increases from 1.27 to 2.03 , and the maximum void ratio $e_{\max }$ and the minimum void ratio $e_{\min }$ of the numerically simulated specimen, as well as the void ratio $e$ that corresponds to the RD of 0.89 , decrease. With the increasing fractal dimension $D$, the scale method changes, and the number of fine particles contained in the specimen increases gradually with the number of contacts between the inner particles. However, the number of contacts is closely related to the compactness. A high content of fine particles corresponds to great compactness and low void ratio. For smooth round particles without breakage, a small particle size corresponds to great compactness and a large fractal dimension $D$.

\subsection{Biaxial Compression Test}

To eliminate the influences of different compactness on the macroscopic strength and deformation characteristics of the specimen, the RD (0.89) is taken to prepare the numerically simulated specimens that are made by the four different scale methods, and the specimen size is $\varphi 300 \mathrm{~mm} \times 600 \mathrm{~mm}$. In this paper, the linear stiffness model without considering particle breakage is adopted, and the calibration of meso parameters refers to references $[29,30]$. The mesonumerical parameters are set as follows: the modulus of elasticity is $2.0 \mathrm{GPa}$; the ratio of the normal contact stiffness of the particle to the tangential contact stiffness is 1.5 ; the friction coefficient between the particles is 0.48 ; the friction factor between the particle and the rubber film and that between the particle and the compression plate is 0.001; and the density is $2.45 \mathrm{~g} / \mathrm{cm}^{3}$. 
Figure 4 shows the deviatoric stress and volumetric strain with axial strain under different fractal dimensions $D$. At the initial stage of loading, the deviatoric stress increases rapidly with the axial strain, thereby indicating that the rockfill materials has not yet been completely compacted, and as the axial strain advances, the deviatoric stress increases slowly until the peak deviatoric stress is reached. At that stage, the specimen is wholly shrunk, and the volumetric strain of different specimens is greatly affected by the fractal dimension $D$. Without considering particle breakage, after reaching the peak deviatoric stress, the deviatoric stress-axial strain curve exhibits softening, and the entire specimen produces a dilatancy effect, a great fractal dimension $D$ corresponds to a more obvious dilatancy effect. The more fine-grained soil in rockfill materials, the more obvious the shear dilatancy. The numerically simulated deviatoric stress and volumetric strain with axial strain curve fluctuates violently, because particles with a particle size of $5 \mathrm{~mm}$ are substituted equivoluminally for particles with a particle size smaller than $5 \mathrm{~mm}$. Without the filling of smaller particles, the sliding and rolling of large particles become relatively easy. Thus, the particle aggregate changes the dilatancy significantly.
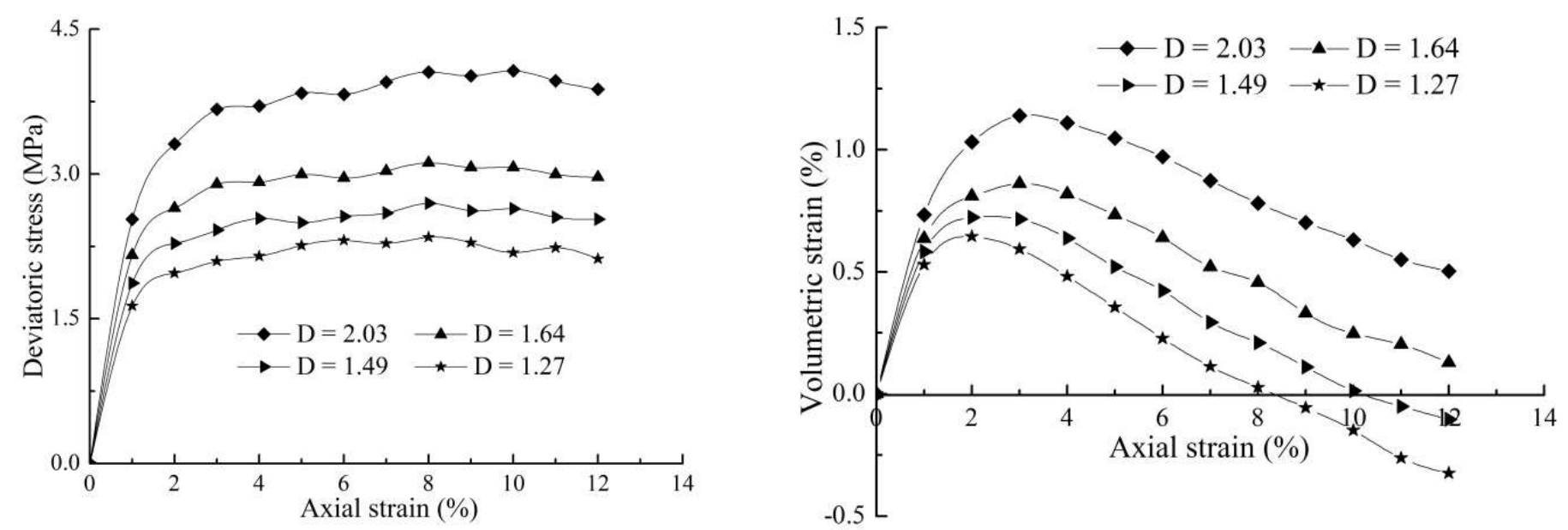

Figure 4. Relation curves of deviatoric stress and volumetric strain with axial strain under different fractal dimensions.

Figure 5 shows that the fractal dimension $D$ greatly affects the mechanical properties of the numerically simulated specimen. The peak internal friction angle of the specimen and the secant modulus rise with the fractal dimension $D$, because an increase in the number of fine particles in the specimen increases the friction between particles and intensifies the sliding and rolling of particles, with the peak deviatoric stress increasing. An increase in the content of fine particles improves the filling of particles, thereby forming a more stable and dense structure with minor axial deformation under the initial stress, but the secant modulus of the specimen increases. The Poisson's ratio of the specimen decreases with the fractal dimension $D$, thereby indicating that a large number of fine particles in the specimen corresponds to evident aggregate interlock behavior and thus weak lateral deformation of the specimens. The peak internal friction angle of the specimen, the secant modulus, and the Poisson ratio show better linear fitting with the fractal dimension $D$. 


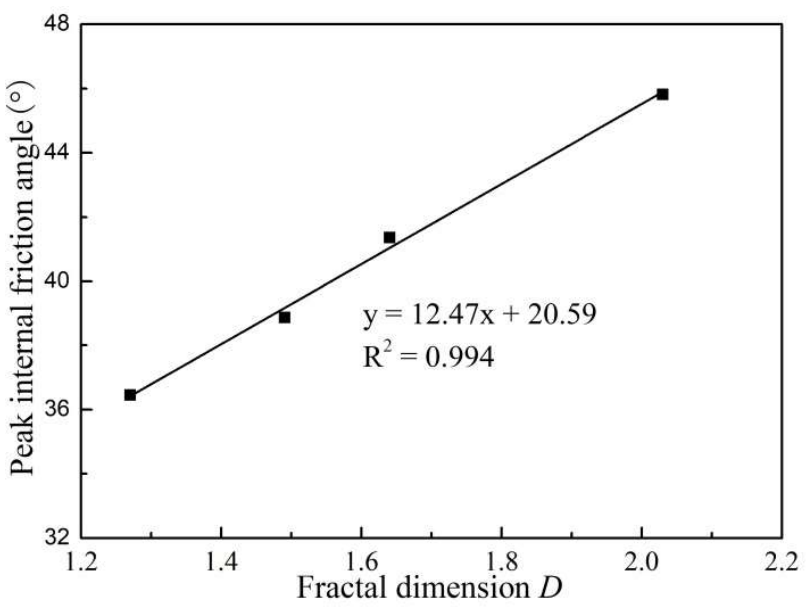

(a)

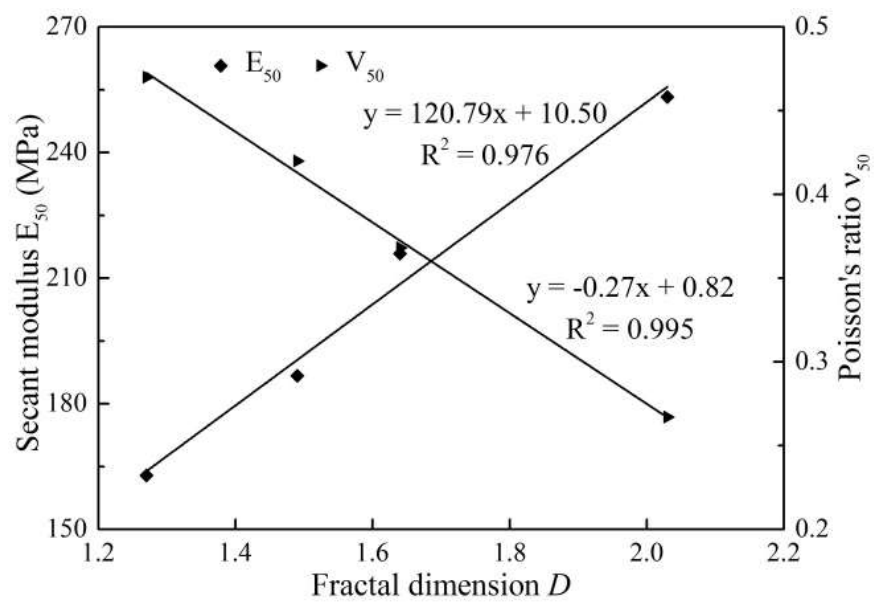

(b)

Figure 5. Relationships between index of strength and deformation characteristics with fractal dimension $D$. (a) strength characteristics, (b) deformation characteristics.

\subsection{Micromechanical Response}

The numerical simulation allows the real-time monitoring of the evolution of rockfill materials in the mesostructure [14,15]. The coordination number $M$ refers to the average number of contacts in the specimen that reflects the contact characteristics of rockfill materials from a meso point of view A great coordination number corresponds to more compact filling of coarse particles and thus higher structure stability. The evolutionary curve of the coordination number is shown in Figure 6. Figure 6 shows that in the initial stage of loading, the finer particles are gradually filled between the coarse particles, the contact points between the particles are increasing, the corresponding coordination number is also increasing, and the sample is in a compressed state; After the coordination number reaches the maximum value, with the continuous increase of load, relative sliding occurs between some coarse particles, the number of contact points between particles decreases, the corresponding coordination number decreases, and the sample is in the state of shear expansion; The coordination number changes corresponding to the four fractal dimensions $D$ are similar. The larger the fractal dimension $D$ is, the larger the coordination number is, but it does not coincide, indicating that the influence of fractal dimension $D$ on numerical simulation calculation is objective.

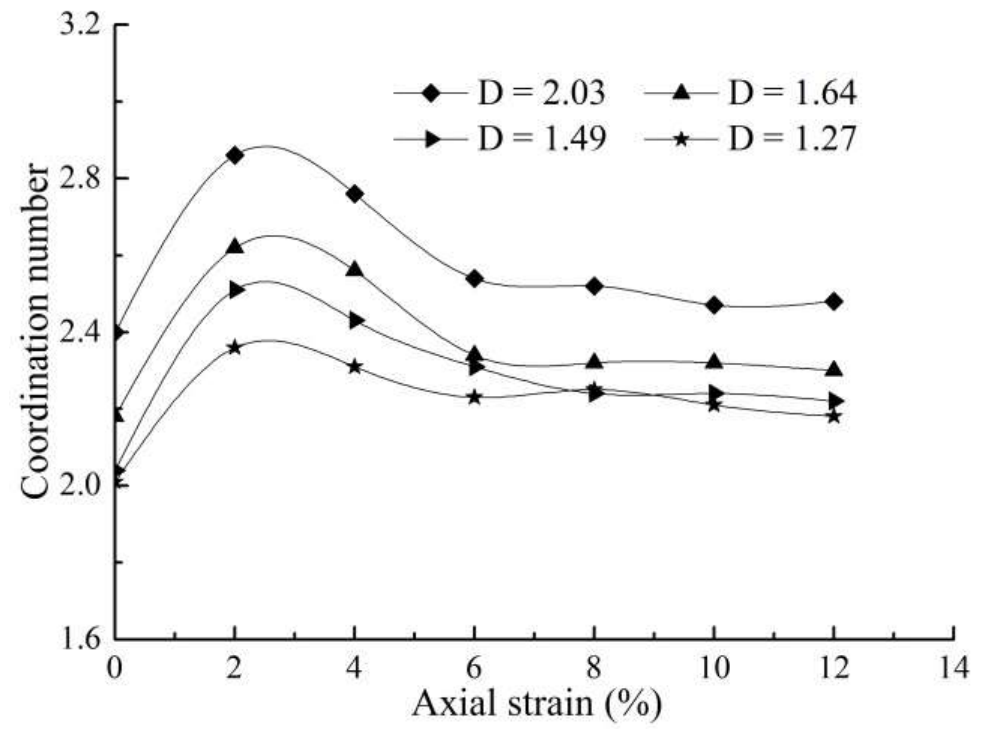

Figure 6. Evolutionary curves of the coordination number. 


\section{Conclusions}

Based on the fractal theory, a fractal model is established with the number of particles between different particle groups as the statistical number. The relationship between the fractal dimension $D$ and different mechanical performance indexes is discussed. Several conclusions can be drawn as follows:

(1) With the use of the particle flow code in two dimensions and on the basis of fractal theory, a fractal model was established with the number of particles used as the statistics. Compared with the specimens obtained by equivalent substitution, which considerably disturbed the particle size distribution, the numerically simulated specimens obtained by the other three scale methods exhibited better fractal characteristics.

(2) A great fractal dimension $D$ corresponds to more obvious deviatoric stress curve softening and volumetric strain curve dilatancy and thus a larger peak deviatoric stress. The peak internal friction angle of the specimen $\varphi_{\mathrm{p}}$, the secant modulus $E_{50}$, and the Poisson's ratio $v_{50}$ show better linear fitting with fractal dimension $D$.

(3) The fractal dimension $D$ often changes the mechanical properties of the specimen with certain macro-responses, that is, with the increasing fractal dimension $D$, the compactness indicators $e_{\max }, e_{\min }$, and $e$ decrease little by little, the strength indicator $\varphi_{\mathrm{p}}$ increases gradually, the deformation indicator $v_{50}$ diminishes, and $E_{50}$ rises. A meso-response is that the fractal dimension $D$ increases with the coordination number.

(4) Using the particle aggregate model, which is used to calculate the rockfill materials in accordance with the fractal theory, the relationship between fractal dimension, peak strength and confining pressure of rockfill materials is established. The limit value of particle breakage is given by using fractal dimension.

Author Contributions: Conceptulization, H.H.; Data curation, Y.M.; Writing-review, W.H. and W.Y.; Supervision, X.F. All authors have read and agreed to the published version of the manuscript.

Funding: This research was funded the National Nature Science Foundation of China (No. 51978540), the Doctor foundation of Xinxiang University (No. 1366020159).

Institutional Review Board Statement: Not applicable.

Informed Consent Statement: Not applicable.

Data Availability Statement: Not applicable.

Conflicts of Interest: The authors declare no conflict of interest.

\section{References}

1. Ahad, B.K.; Mirghasemi, A.S. Numerical and experimental direct shear tests for coarse-grained soils. Particuology 2009, 7, 83-91.

2. Alonso, E.; Olivella, S.; Soriano, A.; Pinyol, N.; Esteban, F. Modelling the response of Lechago earth and rockfill dam. Géotechnique 2011, 61, 387-407. [CrossRef]

3. Honkanadavar, N.P.; Sharma, K.G. Testing and modeling the behavior of riverbed and blasted quarried rockfill materials. Int. J. Géoméch. 2014, 14, 04014028. [CrossRef]

4. Xiao, Y.; Liu, H.; Chen, Y.; Jiang, J.; Zhang, W. State-dependent constitutive model for rockfill materials. Int. J. Géoméch. 2015, 15, 04014075. [CrossRef]

5. Nie, Z.; Zhu, Y.; Wang, X.; Gong, J. Investigating the effects of Fourier-based particle shape on the shear behaviors of rockfill material via DEM. Granul. Matter 2019, 21, 22. [CrossRef]

6. Ovalle, C.; Frossard, E.; Dano, C.; Hu, W.; Maiolino, S.; Hicher, P.Y. The effect of size on the strength of coarse rock aggregates and large rock-fill samples through experimental data. Acta Mech. 2014, 225, 2199-2216. [CrossRef]

7. Tabibnejad, A.; Heshmati, A.; Salehzadeh, H.; Tabatabaei, S.H. Effect of gradation curve and dry density on collapse deformation behavior of a rockfill material. KSCE J. Civ. Eng. 2014, 19, 631-640. [CrossRef]

8. Yang, G.; Yan, X.; Nimbalkar, S.; Xu, J. Effect of Particle Shape and Confining Pressure on Breakage and Deformation of Artificial Rockfill. Int. J. Geosynth. Ground Eng. 2019, 5, 15. [CrossRef]

9. Yao, F.; Ma, G.; Guan, S.; Chen, Y.; Liu, Q.; Feng, C. Interfacial Shearing Behavior Analysis of Rockfill Using FDEM Simulation with Irregularly Shaped Particles. Int. J. Géoméch. 2020, 20, 04019193. [CrossRef]

10. Li, Y.; She, C.X. Discrete Simulation of Vibratory Roller Compaction of Field Rockfills. Shock and Vib. 2021, $2021,9246947$. [CrossRef] 
11. Seo, M.-W.; Ha, I.S.; Kim, Y.-S.; Olson, S.M. Behavior of concrete-faced rockfill dams during initial impoundment. J. Geotech. Geoenviron. Eng. 2009, 135, 1070-1081. [CrossRef]

12. Choo, Y.W.; Shin, N.H.; Cho, S.E.; Im, E.S.; Kim, N.-S. Seepage behavior of drainage zoning in a concrete faced gravel-fill dam via centrifuge and numerical modeling. KSCE J. Civ. Eng. 2013, 17, 949-958. [CrossRef]

13. Matteo, A.; Giuseppe, M.; Paolo, C.; Russo, G. Assessment of the seismic performance of a bituminous faced rockfill dam. Soil Dyn. Earthq. Eng. 2015, 75, 183-198.

14. Bagherzadeh-Khalkhali, A.; Mirghasemi, A.A.; Mohammadi, S. Micromechanics of breakage in sharp-edge particles using combined DEM and FEM. Particuology 2008, 6, 347-361. [CrossRef]

15. Han, H.X.; Chen, W.; Qiu, Z.F.; Fu, X.D. Numerical simulation of two-dimensional particle flow in broken rockfill materials. Chin. J. Geotech. Eng. 2016, 38, 234-239.

16. Mandelbrot, B.B. The Fractal Geometry of Nature; W.H. Freeman: San Francisco, CA, USA, 1982.

17. Kruhl, J.H. Fractal-geometry techniques in the quantification of complex rock structures: A special view on scaling regimes, inhomogeneity and anisotropy. J. Struct. Geol. 2013, 46, 2-21. [CrossRef]

18. Castrignanò, A.; Stelluti, M. Fractal geometry and geostatistics for describing the field variability of soil aggregation. J. Agric. Eng. Res. 1999, 73, 13-18. [CrossRef]

19. Tyler, S.W.; Wheatcraft, S.W. Fractal scaling of soil particle-size distributions: Analysis and limitations. Soil Sci. Soc. Am. J. 1992, 56, 362-369. [CrossRef]

20. Wu, L.; Zhu, S.; Wang, Y.; Lu, C.; Dend, S. The properties of scale effect on the density of rockfill material based on fractal theory. Iran. J. Sci. Technol.-Trans. Civ. Eng. 2015, 39, 183-200.

21. Xiao, Y.; Meng, M.; Daouadji, A.; Chen, Q.; Wu, Z.; Jiang, X. Effects of particle size on crushing and deformation behaviors of rockfill materials. Geosci. Front. 2020, 11, 375-388. [CrossRef]

22. Wu, L.; Zhu, S.; Wang, Y.; Wei, K.; Lu, C. A modified scale method based on fractal theory for rockfill materials. Eur. J. Environ. Civ. Eng. 2014, 18, 106-127. [CrossRef]

23. Wu, L.Q.; Zhu, S.; Wei, K.M.; Lu, C.Y. The fractal properties of scale effect on the density of rock-fill materials. Adv. Mater. Res. 2013, 706-708, 520-525. [CrossRef]

24. Turcotte, D.L. Fractals and fragmentation. J. Geophys. Res. Space Phys. 1986, 91, 1921-1926. [CrossRef]

25. Bouzeboudja, A.; Melbouci, B. Study of the evolution of the fractal dimension of a granular material's grains during mechanical tests. Bull. Eng. Geol. Environ. 2016, 75, 821-839. [CrossRef]

26. Hou, T.-X.; Xu, Q.; Zhou, J.-W. Size distribution, morphology and fractal characteristics of brittle rock fragmentations by the impact loading effect. Acta Mech. 2015, 226, 3623-3637. [CrossRef]

27. Muto, J.; Nakatani, T.; Nishikawa, O.; Nagahama, H. Fractal particle size distribution of pulverized fault rocks as a function of distance from the fault core. Geophys. Res. Lett. 2015, 42, 3811-3819. [CrossRef]

28. Zhu, J.G.; Weng, H.Y.; Wu, X.M.; Liu, H.L. Experimental study of compact density of scaled coarse-grained soil. Rock Soil Mech. 2010, 31, 2394-2398.

29. Zhou, B.; Wang, H.B.; Zhao, W.F.; Li, J.W.; Zheng, B.C. Analysis of relationship between particle mesoscopic and macroscopic mechanical parameters of cohesive materials. Rock Soil Mech. 2012, 33, 3171-3178.

30. Han, H.X.; Chen, W.; Huang, B.; Fu, X.D. Numerical simulation of the influence of particle shape on the mechanical properties of rockfill mate-rials. Eng. Comput. 2017, 34, 2228-2241. [CrossRef] 